\title{
A PARTICIPAÇÃO DE LIDERANÇAS ORIUNDAS DE MOVIMENTOS SOCIAIS NO ESTADO: DINÂMICAS POLÍTICAS, TRÂNSITOS E TENSÕES ${ }^{12}$
}

\author{
Brena Costa Lerbach ${ }^{3}$
}

\begin{abstract}
Resumo
Tendo em vista o frequente percurso observado na trajetória política de lideranças que, originadas em movimentos sociais, passam a ocupar cargos em instituições estatais, este artigo tem como objetivo discutir possibilidades na construção de uma abordagem teórica direcionada ao estudo do trânsito de ativistas de movimentos sociais para o Estado. Para tanto, realiza uma discussão teórica a respeito das relações entre movimentos sociais e Estado, atentando para as insuficiências apresentadas pelas teorias que se dedicam ao estudo dos movimentos sociais; e propõe o desenvolvimento de abordagens que compreendam tais trânsitos de maneira a considerar seu caráter dinâmico, tenso e contextual.
\end{abstract}

Palavras-chave: Liderança; Ativismo; Relação Movimentos Sociais-Estado.

\begin{abstract}
In view of the frequent path observed in political trajectories of leaders who, coming from social movements, start to hold positions in state institutions, this article aims to discuss possibilities in the construction of a theoretical approach on the the transit of activists from social movements to State. Therefore, it develops a theoretical discussion about the relationship between social movements and State, paying attention to the shortcomings presented by the theories devoted to social movements study; and proposes the development of approaches which understand such transits in order to consider its dynamic, tense and contextual character.
\end{abstract}

Keywords: Leadership; Activism; Social Movements-State Relationship.

\section{Resumen}

En vista del camino con frecuencia observado en la carrera política de líderes que, originados en los movimientos sociales, llegan a ocupar posiciones en las instituciones del Estado, este artículo tiene como objetivo discutir las posibilidades en la construcción de una aproximación teórica centrada en el estúdio del tránsito de activistas de los movimientos sociales al Estado. Para eso, realice una discusión teórica sobre la relación entre movimientos sociales y Estado, poniendo atención a las deficiencias que presentan las teorías que se dedican al estudio de los movimientos sociales; y propone el desarrollo de enfoques para entender tales tránsitos a fin de considerar su carácter dinámico, tenso y contextual.

Palabras-clave: Liderazgo; Activismo; Relácion Movimientos Sociales-Estado.

\section{INTRODUÇÃO}

Nos últimos anos os estudiosos dos movimentos sociais vêm indicando mudanças nas relações entre movimentos e Estado. Ao contrário da externalidade e da conflitualidade que caracterizavam esta relação na literatura dominante e, de maneira geral, no contexto anterior brasileiro (no qual os movimentos colocavam-se "de costas" para o Estado, evitando

\footnotetext{
${ }^{1}$ DOI deste artigo: $10.5380 /$ recp.v6i2.37389.

2 Uma versão preliminar deste trabalho foi apresentada na Terceira Jornada de Ciências Sociais da Universidade Federal de Juiz de Fora, ocorrida entre os dias 16 e 19 de setembro de 2014.

${ }^{3}$ Mestranda em Ciências Sociais pela Universidade Federal do Espírito Santo. E-mail: brenalerbach@gmail.com
} 
alianças a fim de se protegerem de uma colonização e para permanecerem fiéis aos seus princípios), as análises empíricas mais recentes apontam que os movimentos sociais podem desenvolver uma relação bastante estreita com o Estado. Esta mudança de quadro teve início a partir do processo de redemocratização, no final da década de $1980^{4}$, quando vários movimentos sociais deram origem a partidos políticos e quando foram criados espaços destinados à consulta e deliberação junto à sociedade civil, principalmente no que diz respeito às políticas públicas. Desde então, os movimentos têm atuado conjuntamente com o Estado em projetos, buscado nele financiamento, e fornecido consultoria para criação e implementação de políticas públicas. Em vários casos, lideranças de movimentos sociais passam a atuar dentro do próprio Estado, assumindo cargos na administração pública. Nesses casos, vale ressaltar que este trânsito é em muito possibilitado pela vinculação a um partido político.

Tendo em vista este cenário, no qual não apenas o poder ${ }^{5}$, mas os próprios atores políticos estão em movimento, o texto que ora apresentamos tem como objetivo chamar a atenção para a importância do estudo dos trânsitos de lideranças oriundas de movimentos sociais para o Estado, quando passam a ocupar cargos (sejam estes comissionados ou de confiança - e, em alguns casos, eletivos) no aparato estatal - fenômeno que, como nossa breve discussão pretende destacar, não foi suficientemente abordado pelas duas principais vertentes teóricas sobre movimentos sociais desenvolvidas na virada para o século XXI: as teorias sobre a sociedade civil e o confronto político. Tem como objetivo, também, propor uma compreensão de tais relações fundada no estudo das dinâmicas políticas que são específicas de cada caso, sem, contudo, desconsiderar o tensionamento latente presente nas relações entre movimento e Estado. Sendo assim, o presente texto encontra-se dividido em duas partes. Na primeira, falaremos sobre a relação entre movimentos sociais e Estado a partir de uma perspectiva crítica à teoria, buscando, para além de um simples resgate, apontar limites e lacunas existentes neste campo acadêmico. E, a partir da percepção de que um aprofundamento analítico sobre o tema é necessário, desenvolveremos, na segunda parte,

\footnotetext{
${ }^{4}$ Muito embora alguns trabalhos apontem a anterioridade de relações de proximidade entre movimentos e Estado no Brasil, bem como a existência de casos de "infiltração" de ativistas em órgãos públicos. Vide Falleti (2010).

5 Alusão ao livro O poder em movimento: Movimentos sociais e confronto político, de Sidney Tarrow (2009), e também à abertura para a participação na política institucional lograda com a redemocratização.
} 
uma argumentação que aponta a direção teórica escolhida como possível solução aos dilemas encontrados. O texto é finalizado com algumas breves considerações.

\section{A RELAÇÃO ENTRE MOVIMENTOS SOCIAIS E ESTADO A PARTIR DE UMA PERSPECTIVA CRÍTICA À TEORIA ${ }^{6}$}

O termo "movimentos sociais" foi empregado na década de 1960 com a finalidade de tratar de uma série de movimentos "de novo tipo", que não tinham como objetivo tomar o Estado ou nele interferir diretamente, atuando por meio da persuasão e voltando os discursos também para a própria sociedade. Tais movimentos não possuíam apenas demandas materiais ou redistributivas, trazendo para o debate questões identitárias, de reconhecimento, referentes à qualidade de vida, ao comportamento, etc. (Alonso, 2009). Desde então, o campo teórico passou por uma série de mudanças, sendo vários os desenvolvimentos conceituais e analíticos. Mudou também o campo empírico: com demandas, formas de atuação e discursos variados, e desenvolvendo-se em contextos muito diversos, os movimentos sociais são considerados um fenômeno altamente complexo, dinâmico e fluido - qualidades intensificadas na contemporaneidade "global" e tecnológica.

Foi entre as décadas de 1970 e 1980 que o campo de estudos foi configurado. Após embates e reelaborações teóricas por parte dos estudiosos vinculados às três principais abordagens teóricas que se desenvolveram na década de 1970 (as teorias da mobilização de recursos, do processo político e dos novos movimentos sociais $)^{7}$, os movimentos sociais ${ }^{8}$ “(...) têm sido compreendidos como uma forma de ação coletiva sustentada, a partir da qual atores que compartilham identidades e solidariedades enfrentam estruturas sociais ou práticas culturais dominantes (Abers e Von Bülow, 2011: 53)”.

Das correntes teóricas mencionadas, originaram-se dois movimentos analíticos durante a década de 1990, os quais propunham ampliar as fronteiras do objeto de análise: as

\footnotetext{
${ }^{6} \mathrm{O}$ texto que compõe esta seção foi retirado do trabalho "Lacunas teóricas acerca da participação de lideranças de movimentos sociais no Estado”, por mim apresentado no II Colóquio do Grupo de Estudos e Pesquisas em Teoria Política Contemporânea, em dezembro de 2013, na Universidade Federal do Espírito Santo.

${ }^{7}$ Uma boa síntese dessas correntes teóricas é feita por Angela Alonso (2009).

${ }^{8}$ Optamos por utilizar essa definição genérica fornecida por Abers e Von Bülow tendo em vista que, como as próprias autoras mencionam, trata-se de uma visão compartilhada tanto por autores associados à corrente dos novos movimentos sociais, como Alain Touraine e Alberto Melucci, bem como por autores ligados à abordagem do processo político, como Sidney Tarrow.
} 
teorias sobre a sociedade civil e a contentious politics (normalmente traduzida como "confronto" ou "conflito político"). As teorias sobre a sociedade civil encontram suas raízes na literatura dos novos movimentos sociais. São abertamente influenciadas pelo pensamento de Jürgen Habermas, e buscam enfocar a vasta arena situada fora do espaço do Estado e do mercado, onde existiriam (ou deveriam existir) grupos e associações interligadas e engajadas em práticas comunicativas, caracterizadas por valores como respeito mútuo e solidariedade (Abers e Von Bülow, 2011). Houve uma conjunção da teoria da esfera pública, de Habermas, com o conceito de sociedade civil, recuperado por Touraine, a qual foi cristalizada e incrementada no livro Civil Society and Political Theory, de Cohen e Arato, publicado em 1992. Assim, o foco, que estava antes nos movimentos, foi aberto, passando a abranger uma multiplicidade de atores e as arenas públicas. Além disso, as teorias da sociedade civil, articuladas em conjunto com os propósitos normativos da democracia deliberativa, passaram a salientar o consenso no lugar do conflito. Esta perspectiva teórica teve alta ressonância no Brasil e, como consequência, uma grande quantidade de trabalhos sobre participação e democracia deliberativa surgiu no período?.

De outro lado, a abordagem do confronto político foi desenvolvida principalmente por pesquisadores anteriormente associados à teoria do processo político. Também interessados em ampliar as fronteiras do campo de estudos, puseram a ênfase no conflito, em vez de na reciprocidade e na comunicação (Abers e Von Bülow, 2011). A publicação que marca as ideias defendidas por esta vertente é o livro Dynamics of Contention, escrito por Tilly, Tarrow e McAdam. No livro, que foi publicado em 2001, os autores tratam os movimentos sociais como um dos fenômenos pertencentes a uma gama de formas de ação que envolvem confronto, incluindo também partidos, nacionalismos, guerrilhas, terrorismo, guerras civis, revoluções, etc. A abordagem trouxe como agenda a “(...) busca de mecanismos comuns que, em diferentes sequências e combinações, estruturariam toda a variedade de episódios contenciosos" (Alonso, 2009: 76), abrindo espaço, nesse sentido, para o desenvolvimento de trabalhos comparativos. Os autores concentram-se nos tipos de interação (conflituosa), não se prendendo a uma segregação entre as categorias de conflito (como luta sindical, organização não-governamental, associação, movimento social, nacionalismo, etc.), e enfatizando os mecanismos e dinâmicas que lhes são comuns (McAdam, Tilly e Tarrow, 2005).

\footnotetext{
${ }^{9}$ Por exemplo, os trabalhos de Costa (1994), Avritzer (1994), e de Alvarez, Escobar e Dagnino (2000).
} 
Tendo nos situado em relação ao campo teórico, apresentaremos agora uma crítica útil aos objetivos deste trabalho, realizada em um artigo escrito por Rebecca Abers e Marisa Von Bülow (2011). No artigo, as autoras argumentam que, apesar dessa tendência de incorporar novos atores e problemas à análise ser positiva, ambas as abordagens ainda mantêm na invisibilidade certos tipos de relações sociais que podem ser relevantes para a compreensão das ações coletivas e movimentos sociais. Nesta avaliação, as duas abordagens falham ao excluir ou não analisar adequadamente a presença de atores vinculados a movimentos dentro da arena estatal.

Nos trabalhos na linha da sociedade civil aparece o conceito de "autolimitação". Para Cohen e Arato (2000), a sociedade civil deve ser "autolimitada", o que significa que os atores da sociedade civil precisariam constituir um campo separado em relação ao mercado e ao Estado. Tal recomendação funda-se na intenção de que a sociedade civil possa se caracterizar como a esfera pública habermasiana, definida como o espaço social "que se alimenta da liberdade comunicativa que uns concedem aos outros" (Habermas, 1997: 93). Segundo o pensamento de Habermas, os indivíduos apenas teriam liberdade comunicativa para construírem uma verdadeira soberania popular quando a esfera pública estivesse livre de interferências de desigualdades econômicas, de status, ou de hierarquias políticas, pois, nesta situação, a única forma de poder seria o poder do melhor argumento. Dessa forma, como as autoras relatam, a preocupação daquela vertente era com a "colonização" da sociedade civil pela lógica do poder administrativo e pela competição por lucros, que seriam prejudiciais à construção de um espaço para os indivíduos se comunicarem livremente, expressando suas opiniões sobre os problemas da sociedade. No entanto, ao separar rigidamente Estado e sociedade civil, a abordagem impossibilita compreender casos em que ativistas atuam junto ou dentro do Estado. Também exclui grupos relevantes do ponto de vista político e democrático, como as associações que fazem a mediação com o Estado e o mercado, por exemplo, partidos políticos, sindicatos e grupos de consumidores organizados.

A abordagem do confronto político, por sua vez, sustenta uma postura distinta, pois, além de abranger uma multiplicidade de atores, não adota uma separação entre esferas. Ao contrário, não vê descontinuidade entre política institucional e não institucional, afirmando que “(...) o confronto político constitui um terreno analítico contínuo com nada mais do que fronteiras fluidas" (McAdam, Tarrow e Tilly, 2009). Diferentemente das teorias sobre a sociedade civil, dá lugar de destaque ao Estado enquanto parte importante nas 
relações de conflito. Contudo, o foco da abordagem recai sobre as relações de conflito ${ }^{10}$. Para Abers e Von Bülow (2011), esta perspectiva não teria como preocupação principal, portanto, promover análises que tenham como objetivo compreender como ativistas interagem dentro ou em parceria com o Estado. Por fim, a avaliação geral das autoras é de que a literatura, no geral, não tem dado conta do fenômeno da entrada de participantes de movimentos sociais para o Estado. O principal engano estaria na compreensão dos movimentos sociais como sendo inerentemente distintos ou externos em relação ao Estado. Em suas palavras:

Esse pressuposto impede que se capturem algumas das relações complexas que existem entre pessoas no aparato estatal e aquelas que agem a partir de organizações de movimentos sociais. Se pensarmos o Estado como um bloco homogêneo que opera em um espaço organizativo distinto, dificilmente conseguiremos reconhecer redes que cruzam as fronteiras entre Estado e sociedade civil como parte importante dos movimentos sociais. Porém (...) na América Latina - e, em particular, no Brasil - as redes de movimentos sociais muitas vezes cruzam essas fronteiras (Abers e Von Bülow, 2011: 64).

Tendo em vista que os ativistas não apenas interagem, mas, em vários casos, participam diretamente da gestão estatal, as autoras sugerem uma abordagem que utilize as teorias sobre redes, tal como a desenvolvida por Mario Diani - autor que não exclui automaticamente atores estatais do conceito de movimento social ${ }^{11}$. E afirmam que é preciso ir além do estudo do que tradicionalmente entendemos por movimentos sociais. Pensamos, entretanto, que a utilização do conceito de redes precisa ser problematizada quanto a este uso, uma vez que organizações de movimentos sociais e Estado consistem em formas de organização política de naturezas distintas e, com frequência, tensamente relacionadas na realidade social.

\section{A INSERÇÃO DE LIDERANÇAS DE MOVIMENTOS SOCIAIS NO ESTADO}

No ponto anterior falamos sobre como as vertentes da sociedade civil e do confronto político situam movimentos sociais e Estado, e sobre como as relações entre eles são compreendidas. Seja como estando circunscritos a esferas diferentes, seja ocupando

\footnotetext{
${ }^{10}$ Apesar de admitirem que nem toda política envolve conflito, os autores optam por centrar a análise nas interações coletivas que envolvem conflito, ou seja, quando as reivindicações, no caso de serem satisfeitas, afetariam os interesses de outras partes envolvidas (McAdam, Tarrow e Tilly, 2005).

11 Diani definiu os movimentos sociais como "redes de interações informais entre uma pluralidade de indivíduos, grupos ou associações engajados em um conflito político ou cultural, com base em uma identidade coletiva compartilhada" (Diani, 1992 apud Diani e Biason, 2010: 220).
} 
posições distintas, chegamos à conclusão de que uma abordagem da relação entre movimentos sociais e Estado que tenha como foco os trânsitos de ativistas de um campo de atuação para outro ainda carece de esforços e se coloca como desafio para os pesquisadores. Levar em consideração esses trânsitos consiste em uma tarefa necessária quando atentamos para o fato de que a inserção de dirigentes e militantes da sociedade civil no aparato estatal, por meio da ocupação de cargos públicos, tem sido constante no cenário político brasileiro pós-redemocratização (Baltazar, 1998; Dagnino, Olvera e Panfichi 2006; Feltran, 2006; Silva e Oliveira, 2011; Abers e Von Bülow, 2011), e que mudanças nos padrões de relações desenvolvidos com o Estado produzem impactos nas políticas públicas, nas ações e no perfil das próprias $\mathrm{OMSs}^{12}$, na articulação da luta política e mesmo sobre as próprias lideranças que transitaram de um campo de atuação política para outro.

Uma abordagem clássica a respeito da participação de lideranças de movimentos na política institucionalizada é a de Robert Michels, em Sociologia dos Partidos Políticos (1982). Tendo como objeto o movimento operário e sua institucionalização em partidos políticos na Alemanha do começo do século XX, Michels denunciava que a institucionalização levaria à oligarquização, produzindo uma elite de postura conservadora. Como resultado, as lideranças se descolariam de suas bases. O líder operário, que no início de seu envolvimento com os assuntos políticos desenvolveria uma atuação marcada pela atividade oratória, "brilhante e barulhenta", com a participação em iniciativas mais institucionalizadas passaria a ter uma atuação mais sólida, porém mais administrativa. Uma vez em contato com a expertise do Estado e recebendo uma formação técnica e burocrática, o líder se distanciaria do modo de vida dos demais, cujas mãos e rotinas permaneceriam marcadas pelo trabalho operário. Para o autor, este seria "um ciclo natural percorrido por todo representante: oriundo do povo ele acaba acima do povo" (ibidem: 24). Apesar de não considerar que todos os líderes sejam necessariamente carreiristas, o autor frisa o impacto dos interesses econômicos e do status sobre suas escolhas e ações. Segundo ele, ocorreria uma metamorfose psicológica nos chefes: a participação no poder, somada aos efeitos de um avanço no ciclo de vida, causaria mudanças no sistema de crenças dos líderes e, consequentemente, em suas ações. Assim, a

\footnotetext{
12 Organizações de movimentos sociais. Assim como McCarthy e Zald (1977), distinguimos "movimento social" e "organização de movimento social". Enquanto o "movimento social" é por eles compreendido como um conjunto de opiniões e crenças que partem de uma população e expressam reivindicações e preferências para a mudança, OMS é o conceito utilizado para fazer referência aos diversos grupos organizados para ação que identificam seus objetivos com as preferências de um movimento. Apesar de não compreendermos os movimentos sociais como simples conjuntos de preferências, optamos por adotar tal distinção pelo fato de nos permitir diferenciar os movimentos sociais (enquanto forma de ação política contenciosa) dos grupos organizados que neles se engajam (ou seja, de seus atores).
} 
avaliação de Michels é marcadamente negativa: a institucionalização dos movimentos e a participação das lideranças no poder institucionalizado são vistas como algo ruim, conferindo um caráter reformista às lutas e promovendo um aburguesamento de seus representantes.

Avaliações negativas também foram feitas em relação ao caso brasileiro, quando, em função de uma abertura de oportunidades políticas decorrente da redemocratização, a ocupação de posições dentro das instituições estatais por lideranças de movimentos sociais foi possibilitada. O modo de compreender os movimentos sociais, inclusive dentro da academia, foi muito marcado pelo seu contexto de origem, no qual a participação política estava impossibilitada pelo regime ditatorial, e no qual a sociedade civil emergia como campo de luta e resistência, lugar das virtudes políticas e da inovação democrática. Caracterizandoos pela organização "espontânea" e "autônoma", os analistas ${ }^{13}$ ressaltaram a externalidade dos movimentos sociais em relação ao Estado, bem como a ideia de "sociedade contra o Estado" (Silva e Oliveira, 2011). Ao enfatizarem o caráter outsider em relação ao poder político instituído e a conflitualidade entre movimentos e Estado, os autores realizaram uma análise adequada àquele contexto nacional. Contudo, como Silva e Oliveira (ibidem) apontam, ao universalizarem essas características contextuais como algo inerente à natureza da relação entre movimentos sociais e Estado, impossibilitaram a compreensão de outros padrões de relacionamento que podem se desenvolver entre as duas partes, quando, por exemplo, movimentos agem em parceria com o Estado ou como, no caso que aqui nos interessa, quando lideranças oriundas de movimentos sociais passam a ocupar cargos nas instituições estatais.

Com a redemocratização, movimentos sociais, sindicatos e outros atores organizados engajados na luta pela democratização lograram maior permeabilidade para as demandas da sociedade frente às instituições políticas. Unidos pelo compartilhamento de um mesmo projeto "democrático popular", apostaram na possibilidade de uma democratização conjunta do Estado e da sociedade pela articulação entre a via eleitoral e a implementação de canais de participação popular nos governos (Feltran, 2006). Desse debate, emergiram uma série de iniciativas, como o orçamento participativo e os conselhos gestores de políticas públicas. Além disso, com o retorno do multipartidarismo, novos atores da política institucional puderam se organizar, abrindo a possibilidade de mediação entre movimentos e poder político. Diante desse contexto de oportunidades políticas favoráveis à atuação

\footnotetext{
${ }^{13}$ Como Evers (1983), Sader (1988) e Telles (1988).
} 
conjunta entre sociedade civil e Estado e à participação popular, mudanças se processaram na relação entre movimentos sociais e Estado, descortinando-se um quadro muito diverso daquele de alguns anos atrás.

No novo cenário, houve grande entrada de lideranças provenientes de movimentos, associações, sindicatos, etc. na burocracia estatal. Este processo não foi devidamente acompanhado pelos pesquisadores brasileiros, que, nas palavras de Silva e Oliveira (2011), estavam "pouco instrumentalizados" para explicar os novos padrões de relação, uma vez que estes não correspondiam ao modelo teórico-normativo de movimento social da década de 1980. Vistos com as lentes daquela década, os novos padrões interacionais entre sociedade e Estado tenderiam a ser vistos sempre como desviantes, ameaça à autonomia e à combatividade, etc $^{14}$. Segundo os autores, a situação de externalidade seria apenas uma das formatações que a relação entre movimentos e Estado poderia assumir.

Ao abordar a atuação das femocrats - feministas que ocupavam postos nas agências de políticas públicas para mulheres e noutros segmentos da burocracia estatal nos Estados Unidos, Lee Ann Banaszak (2005) chama atenção para a atuação de funcionários do Estado que são ativistas. Em alguns casos, quando suas ações contribuem para o desenvolvimento de iniciativas por parte do Estado em benefício daquela causa, seria, segundo a autora, mais correto analisar tais avanços não como frutos de uma oportunidade política criada por aliados externos ao movimento, mas também como resultado do movimento moldando suas próprias oportunidades. Conforme argumenta, esta tática só poderia ser posta em prática pelos ativistas que cruzam as fronteiras entre Estado e movimento, ou entre o movimento e seus aliados. Ela afirma que, se quisermos compreender táticas, estratégias e resultados dos movimentos sociais, devemos reexaminar os limites entre os movimentos e as outras partes em interação - principalmente o Estado. Assim, contradiz a visão de que para mudar a ordem política o movimento social deve estar fora da polity, enfatizando os casos em que há uma sobreposição de membros, que ela chama de "interseção Estado-movimento". Banaszak contesta também a visão de que, uma vez inseridos nas instâncias do poder institucionalizado, os ativistas passariam a atuar unicamente a partir de táticas insider. em suas pesquisas, observa que ativistas inseridos tendem a atuar dentro do repertório institucional, entretanto, quando não encontram abertura, muitos apoiam e apelam a táticas outsiders. A

\footnotetext{
${ }^{14}$ Escrevo "sempre" em itálico para esclarecer que aqui não me refiro aos trabalhos que apontaram tais características no contexto específico da década de 1990, em relação ao projeto político neoliberal (2004; Dagnino, Olvera e Panfichi, 2006; Feltran, 2006). Tais trabalhos dizem respeito a um contexto e situação específicos, e não a um modelo geral e fixo - que é ao que estamos nos referindo.
} 
inserção de movimentos no Estado é compreendida pela autora em termos de um continuum, que vai da completa inclusão à completa exclusão. Seria necessário analisar, em cada caso, não apenas o número de ativistas inseridos, mas também as diferentes localizações dentro do Estado, e a centralidade ou marginalidade das posições ocupadas.

Assim como Banaszak, não partilhamos da ideia de que as relações entre movimentos sociais e Estado devam ser compreendidas sob a perspectiva da existência de duas esferas nitidamente separadas - os trânsitos entre as duas áreas de atuação acontecem, mostrando que, em muitos casos, as linhas que as dividem encontram-se borradas. Nesse sentido, podemos observar: situações de afinidade e vinculação entre OMSs e partidos, os quais possibilitam o acesso das primeiras às instituições estatais; a existência de projetos políticos diversos que perpassam os campos institucional e não-institucional da política, e que podem promover cooperação e abrir portas para ativistas em setores do Estado (Dagnino, Olvera e Panfichi, 2006); o fenômeno da "militância múltipla" (Mische, 2008), por meio do qual sujeitos podem estar vinculados a diferentes espaços e instituições (ONGs, entidades religiosas, universidade, etc.) de forma simultânea; etc.

Todavia, se a existência de militância múltipla e do trânsito de lideranças para instituições estatais é um fato, por outro lado, pensamos que a vinculação simultânea a espaços que funcionam sob lógicas e escopos diferentes não se dá sem tensões. A ação individual não poderá em quaisquer circunstâncias satisfazer paralelamente ao que demandam movimento e Estado. Nesse sentido, acreditamos existir uma tensão latente decorrente do estado de "duplo pertencimento" - relação expressa na Figura 1, que poderá se manifestar ou não, e em maior ou menor grau, dependendo de elementos contextuais e do acordo (ou desacordo) entre as orientações e agendas desenvolvidas pelas lideranças no movimento em relação àquelas desenvolvidas no Estado. Assim, se concordamos que o trânsito de pessoas entre movimentos sociais e Estado existe e deve ser abordado pela teoria, não nos parece evidente que ele se dê de forma fluida ou natural, devendo ser investigados os tensionamentos e impactos que resultam da mudança na esfera de atuação. 
Imagem 1 - Tensão latente decorrente da dupla vinculação ao movimento e ao Estado

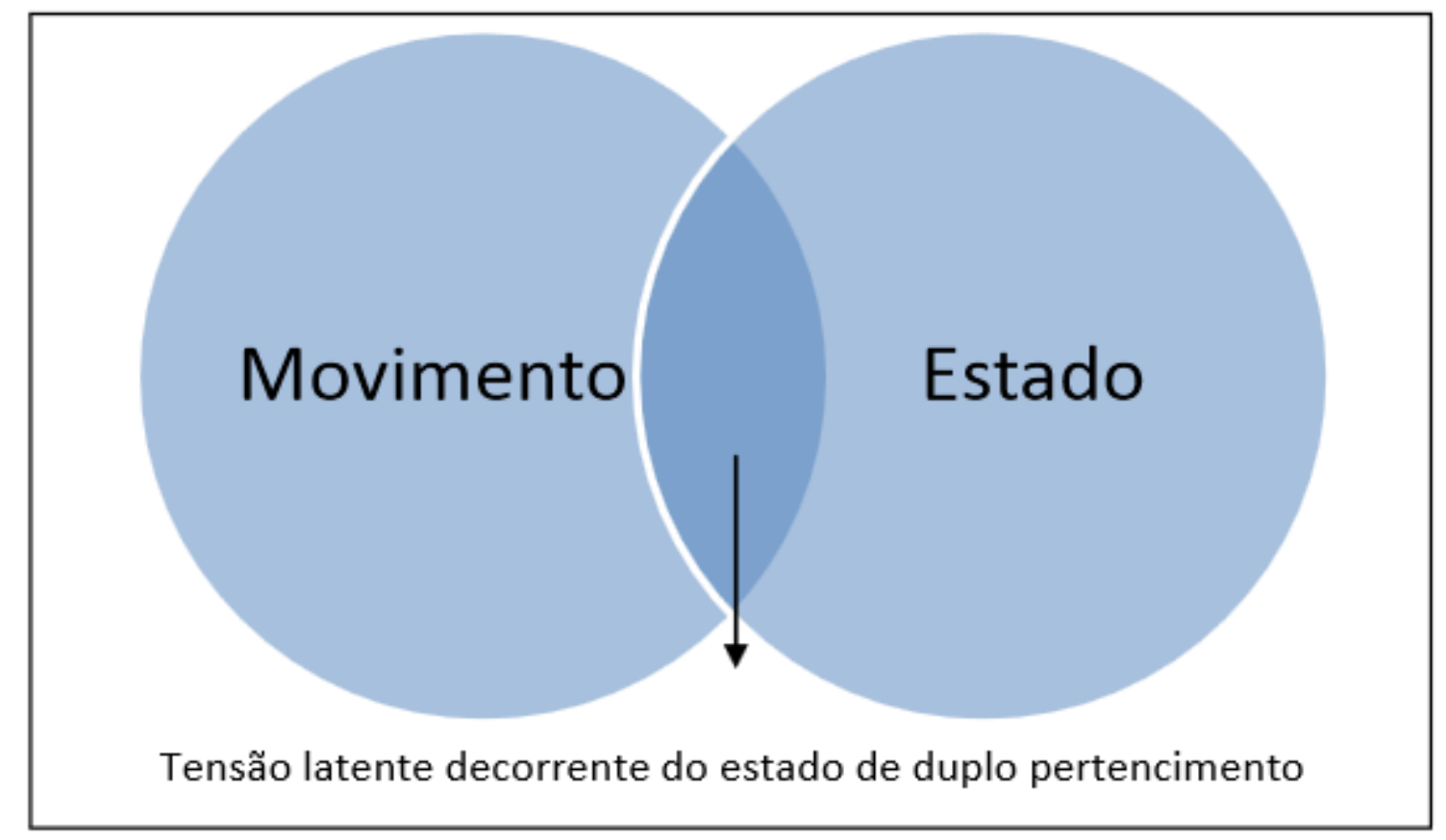

Fonte: Elaboração própria.

Com relação a este aspecto, Feltran (2006), ao estudar a trajetória de militantes que, oriundos da sociedade civil, passaram a desempenhar funções no Estado, obtém depoimentos sobre a dificuldade sentida pelos indivíduos entrevistados no que diz respeito ao relacionamento com os segmentos da sociedade civil com quem formavam uma base de apoio. A partir do "novo lugar social que passavam a ocupar", deveriam atuar pelos parâmetros públicos, atuando para o conjunto da sociedade - algo que em alguns momentos não foi muito bem compreendido por alguns setores populares que, ao perceberem a inserção do grupo aliado na administração estatal, pressionaram por uma liberação imediata de recursos. Na mesma linha, Dagnino et al (2006) sublinha que, a despeito da afinidade que tenham com certo movimento, para governar, os partidos precisam responder a bancos, grupos empresariais, a compromissos eleitorais feitos com outros partidos e grupos, etc.; e que o "lugar" de atuação dos atores (com sua lógica, condições estruturas e funções específicas) pode absorver, neutralizar ou impor uma resignificação de projetos ao longo de dada trajetória:

Observamos também que o lugar de atuação dos atores cria tanto oportunidades como restrições para a ação política, as quais, sob certas circunstâncias, podem produzir deslocamentos e redefinições de sentido nos projetos que se transferem da sociedade civil e partido para o Estado. 
E que a participação dos ativistas em distintas organizações e projetos é resultado de motivações pessoais, sociais e políticas (Ibidem: 82).

Dessa forma, investigações a respeito dos impactos produzidos pelo trânsito de lideranças para o Estado - que saem da posição de desafiantes para a posição de membros da polity - sobre a dimensão individual e sobre a OMS e, mais amplamente, sobre o campo de ativismo em questão, podem trazer conhecimento sobre como a inserção no âmbito estatal pode ser compreendida. Para tratar adequadamente a questão, acreditamos ser preciso levar em consideração aspectos conjunturais relacionados ao contexto político específico; as constelações de forças atuantes; a heterogeneidade dos campos da sociedade civil e estatal e a relativa fluidez de suas fronteiras; assim como a existência de orientações com as quais se alinham ou se opõem grupos alocados nas duas esferas, facilitando ou dificultando trânsitos e alianças. Assim, longe de afirmar que o trânsito de lideranças de uma esfera para a outra deva significar necessariamente cooptação ou a perversão de seus propósitos iniciais, acreditamos que qualquer tentativa de análise da relação entre movimentos e Estado deverá resultar de investigações específicas, com relação às dinâmicas que lhes são específicas. E que os trânsitos, quando ocorrerem, não estarão isentos de contradições e tensões.

\section{CONSIDERAÇÕES FINAIS}

Tendo em vista toda essa discussão, sente-se a necessidade de um aprofundamento nos estudos que tratam das relações entre formas institucionalizadas e não institucionalizadas de fazer política. É nessa direção que Jack Goldstone, no livro States, parties, and social movements (2003), argumenta, afirmando que esta urgência resulta do fato de as instituições estatais e os partidos políticos estarem interpenetrados por movimentos sociais, atuando não apenas em resposta aos movimentos, mas também associados a eles. Assim, acreditamos que a realização de estudos empíricos sobre como líderes militantes constroem um estreito relacionamento com o Estado, chegando mesmo à ocupação de cargos, possa contribuir para a teoria. Pois, como sinalizam os teóricos do confronto político, os movimentos “(...) no representan objetos fijos, impenetrables, claramente delimitados, sino abstracciones de los observadores a partir de unas interacciones continuamente negociadas entre personas y conjuntos de personas" (McAdam, Tarrow e Tilly, 2005: 13). Marca-se, portanto, a necessidade de compreender os movimentos sociais em sua relação com os demais atores e instituições, na complexidade que caracteriza suas dinâmicas políticas. 


\section{REFERÊNCIAS}

ABERS, R,; VON BÜLOW, M. 2011. Movimentos sociais na teoria e na prática: como estudar o ativismo através da fronteira entre Estado e sociedade? In: Sociologias. Porto Alegre, ano $13, n^{\circ} 28$, p. $52-84$.

ALONSO, A. 2009. As teorias dos movimentos sociais: um balanço do debate. Lua Nova, São Paulo, 76, p. 49-86.

ALVAREZ, S.; DAGNINO, E.; ESCOBAR, A. (orgs.). 2000. Cultura e política nos movimentos sociais latino-americanos: novas leituras. Belo Horizonte: Ed. UFMG.

AVRITZER, L. 1994. Sociedade civil e democratização. Belo Horizonte: Del Rey.

BALTAZAR, B. 1998. Quando a militância e a vida cotidiana se (des)encontram: Um estudo das concepções de lideranças sobre as relações do movimento popular com suas vidas. Vitória, Espírito Santo. Dissertação (Mestrado em Psicologia) - Universidade Federal do Espírito Santo.

BANASZAK, L. A. 2005. Inside and outside the state: movement insider status, tactics and public policy achievements. In: MEYER, D. S.; JENNESS, V.; INGRAM, H. (eds.). Routing the opposition: social movements, public policy, and democracy. Minneapolis: University of Minnesota Press.

COHEN, J.; ARATO, A. 2000. Sociedad civil y teoría política. Ciudad del México: Fondo de cultura económica.

COSTA, S. 1994. Esfera pública, redescoberta da sociedade civil e movimentos sociais no Brasil. Uma abordagem tentativa. Novos Estudos Cebrap, n. ${ }^{\circ}$ 38, p. 38-52.

DAGNINO, E.; OLVERA, A. J.; PANFICHI, A. 2006. Para uma outra leitura da disputa pela construção democrática na América Latina. In: DAGNINO, E. et al. (orgs.) A disputa pela construção democrática na América Latina. São Paulo: Paz e Terra.

DIANI, M.; BISON, I. 2010. Organizações, Coalizões e Movimentos. Revista Brasileira de Ciência Política, n.3, Brasília, p. 219-250.

EVERS, T. 1983. De costas para o Estado, longe do Parlamento. Novos Estudos Cebrap, 2 (1), p. 25-39.

FALLETI, T. G. 2010. Infiltrando o Estado: a evolução da reforma da saúde no Brasil, 19641988. Estudos de Sociologia. Araraquara, v.15, n.29, p.345-368.

FELTRAN, G. S. 2006. Deslocamentos - trajetórias individuais, relações entre sociedade civil e Estado no Brasil. In: DAGNINO, E. et al. (orgs.) A disputa pela construção democrática na América Latina. São Paulo: Paz e Terra. 
GOHN, M. G. 2005. O protagonismo da sociedade civil: movimentos sociais, ONGs e redes solidárias. São Paulo: Cortez.

GOHN, M. G. 2008. Teorias dos Movimentos Sociais: paradigmas clássicos e contemporâneos. São Paulo: Edições Loyola.

GOLDSTONE, J. A. 2003. Introduction: Bridging institucionalized and noninstitucionalized politics. In: GOLDSTONE, Jack A. (Editor) States, Parties and Social Movements. Nova Iorque: Cambridge University Press.

HABERMAS, J. 1997. Direito e democracia: entre facticidade e validade, volume II. Rio de Janeiro: Tempo Brasileiro.

MCADAM, D.; TARROW, S.; TILLY, C. 2009. Dinámica de la contienda politica. Barcelona: Hacer Editorial.

MCADAM, D.; TARROW, S.; TILLY, C. 2009. Para mapear o confronto político. Lua Nova, São Paulo, 76, p. 11-48.

MCCARTHY, J. D.; ZALD, M. N. 1976. Resource Mobilization and Social Movements: A Partial Theory. American Journal of Sociology 82, p. 1212-41.

MICHELS, R. 1982. Sociologia dos Partidos Políticos. Brasília: Ed. Unb.

MISCHE, A. 2008. Partisan Publics: Communication and Contention across Brazilian Youth Activist Networks. Nova Jersey (EUA): Princeton University Press.

SADER, E. 1998. Quando novos personagens entraram em cena. Rio de Janeiro: Paz e Terra.

SILVA, M. K.; OLIVEIRA, G. L. 2011. A face oculta(da) dos movimentos sociais: trânsito institucional e intersecção Estado-Movimento - Uma análise do movimento de Economia Solidária no Rio Grande do Sul. Sociologias. Porto Alegre, ano 13, nº 28, p. 86-124.

TARROW, S. 2009. Poder em movimento: movimentos sociais e confronto político. Petrópolis: Vozes.

TELLES, V. S. 1988. Anos 70: experiências, práticas e espaços políticos. In: KOWARICK, L. (org.). As lutas sociais e a cidade: São Paulo passado e presente. Rio de Janeiro: Paz e Terra. 